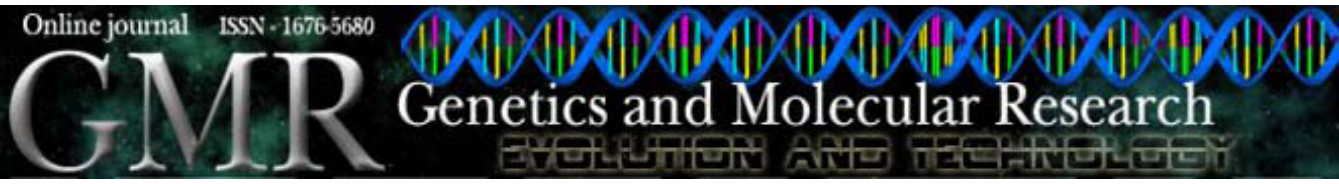

\title{
A minimal DNA cassette as a vector for genetic transformation of soybean (Glycine max)
}

\author{
G.R. Vianna, F.J.L. Aragão and E.L. Rech \\ Embrapa Recursos Genéticos e Biotecnologia, \\ Laboratório de Transferência e Expressão de Genes, \\ Parque Estação Biológica, Brasília, DF, Brasil \\ Corresponding author: G.R. Vianna \\ E-mail: giovanni@cenargen.embrapa.br
}

Genet. Mol. Res. 10 (1): 382-390 (2011)

Received September 8, 2010

Accepted December 11,2010

Published March 1, 2011

DOI 10.4238/vol10-1gmr1058

\begin{abstract}
Currently, the market demands products committed to protecting human health and the environment, known as clean products. We developed a protocol using DNA fragments containing only the gene sequence of interest, to replace the circular vectors containing genes for antibiotic resistance and other undesirable sequences, for obtaining transgenic soybeans for microparticle bombardment. Vector pAC321 was digested with the restriction enzyme $P v u$ II to produce the 6159 bp ahas fragment, which contains the mutated ahas gene from Arabidopsis thaliana (Brassicaceae), under the control of its own promoter and terminator. This gene confers resistance against imazapyr, a herbicidal molecule of the imidazolinone class, capable of systemically translocating and concentrating in the apical meristematic region of the plant, the same region used for the introduction of the transgenes. This fragment was used to generate 10 putative transgenic soybean lines.
\end{abstract}

Key words: Biolistic; Gene transfer; Minimal cassette;

Transformation with DNA fragment; Transgenic soybean 


\section{INTRODUCTION}

Most protocols to produce transgenic plants through direct transformation use plasmid DNA. As a consequence, an array of integration patterns can be obtained, and vector backbone sequences are often found integrated into the plant genome (Vianna et al., 2004). A desirable transgenic locus organization is that where the recipient organism contains as little foreign DNA as possible (Zhao et al., 2007). The vector backbones typically used in plant transformation include a regulatory element for bacterial multiplication and a prokaryotic antibiotic resistance gene as selectable marker, because those are important in the early stages of obtaining DNA on a large scale. The presence of backbone sequences in the plant genome may promote transgene rearrangement and exert undesirable negative effects on transgene or endogenous gene expression (Artelt et al., 1991; Jakowitsch et al., 1999; Muller et al., 1999).

In an attempt to minimize this problem, we evaluated the use of $\gamma$-radiation to physically remove selective marker genes previously introduced into the soybean genome; however, this method was inefficient, removing sequences from the plant genome, silencing the gene of interest and producing some abnormal phenotypes such as dwarfism and wrinkled leaves (Tinoco et al., 2006).

Thus, the use of DNA fragments containing only the genes of interest to obtain transgenic plants is the most appropriate procedure. However, there is insufficient information about the ideal conditions for the use of linear DNA cassettes in direct transformation (Cheng et al., 2009). Efforts to achieve transgenic soybean through the biolistic process have made it possible to introduce some agronomic traits. Some of these plants have been introduced into breeding programs in order to generate transgenic commercial plants (Vianna et al., 2004; Rech et al., 2008). In addition, the evaluation of food and environmental security has been carried out. This evaluation includes studying the potential impacts of the introduced foreign gene(s) present in the transgenic product consumed by humans and animals and its correlation with the environment. Among the extensive analyses, concerns have been raised by regulatory agencies, regarding public opinion and the potential possibilities of the transfer of genes conferring antibiotic resistance present in the commercial product to the microorganisms present in the gut or environment. Based on scientific evidence, the Food and Drug Administration (FDA), among other regulatory institutions, recognizes that there is a remote possibility of the transfer of an antibiotic-resistant gene present in the product to the microorganisms present in the gut and environment (US FDA, 1998). There is as yet no clear evidence of a potential deleterious effect from the ingestion of transgenic products carrying antibiotic resistance genes or other marker genes in transgenic plants to humans, animals and the environment (Miki and McHugh, 2004). However, there is an understandable trend to avoid the presence of any additional sequence in the commercial transgenic varieties, such as replication origin, selection markers or any sequence other than the gene corresponding to the desired trait itself (Fu et al., 2000; Aragão et al., 2002; Vianna et al., 2004).

It has been shown in various plant species that the frequency of plant transformation is similar when either the fragment or a circular plasmid is used. However, in rice the transformation frequency was higher using the fragment cassette than using either the circular or a complete linear vector (Fu et al., 2000). In addition, Southern blot analysis revealed a similar pattern of complexity in transgenic plants obtained either by the entire plasmid or a fragment. 
Gao et al. (2007) and Liu et al. (2009) have developed protocols for obtaining transgenic soybean with minimal linear DNA using the pollen tube pathway or in planta ovarydrip transformation. The linear minimal gene cassette was produced by polymerase chain reaction (PCR). Recently, we developed an efficient protocol to produce transgenic soybean plants using a circular vector containing the mutated ahas gene as selective marker (Aragão et al., 2000; Nunes et al., 2006; Rech et al., 2008). The mutated ahas gene was isolated from Arabidopsis thaliana, and the coding sequence is under the control of its own promoter and terminator. This gene confers resistance against imazapyr, a herbicidal molecule of the imidazolinone class, capable of systemically translocating and concentrating in the apical meristematic region of the plant, the same region used for introduction of transgenes. The methodology presented here describes how to prepare and use only a DNA fragment as the vector for introducing foreign genes into the plant genome. The vector corresponds to the expression cassette, instead of circular vectors containing antibiotic resistance genes, and it is used to obtain transgenic soybean plants using the biolistic system.

\section{MATERIAL AND METHODS}

\section{Vector}

The plasmid pAC321 utilized contains the ahas cassette previously isolated from $A$. thaliana under control of its own promoter and terminator (Aragão et al., 2000; Rech et al., 2008). This gene is mutated at position 653 , which results in a substitution of a serine by an asparagine, and confers tolerance to herbicides of the imidazolinone chemical group, such as imazapyr. The ahas gene codes for the acetic acid hydroxy synthase (AHAS), the enzyme that catalyzes the first step in the synthesis of the branched chain amino acids valine, leucine and isoleucine in plants and microorganisms (Sathasivan et al., 1990).

The pAC321 plasmid was prepared using standard maxi prep protocols (Sambrook and Russell, 2001).

\section{DNA fragment preparation}

The vector was digested with the restriction enzyme $P v u I I$, which permits the expression cassette to be removed from the bacterium plasmid vector. For the digestion reaction, 400 $\mu \mathrm{g}$ plasmid DNA was incubated for $3 \mathrm{~h}$ with $600 \mathrm{U} P v u \mathrm{II}\left(1.5 \mathrm{U}\right.$ per each $\mu \mathrm{g}$ DNA), at $37^{\circ} \mathrm{C}$ using buffer B (Promega ${ }^{\circledR}$ ).

The 6159-bp ahas fragment generated was separated from the backbone by electrophoresis on a $1.0 \%$ agarose gel containing ethidium bromide, at $10 \mathrm{~V} / \mathrm{cm}$, and was excised from the gel using a UV transilluminator. The gel piece containing the band was transferred to an electroelution tube (Spectrapor-membrane 18-mm dialysis tubing, MWCO 3500, Thomas Scientific, USA). The end of the dialysis tubing was closed with a plastic clip and filled with 0.5X TBE (1 L 10X TBE: $108 \mathrm{~g}$ Tris base, $55 \mathrm{~g}$ boric acid, $40 \mathrm{~mL} 500 \mathrm{mM}$ EDTA, $\mathrm{pH}$ 8.0). The other tube end was also closed and, as far as possible, any air bubbles were removed.

Electroelution was performed at $80-90 \mathrm{~V}$ for $3 \mathrm{~h}$ without shaking the tube. The current was inverted for $2 \mathrm{~min}$, at 80-90 V, to recover any DNA adsorbed to the membrane, and the solution was then collected from the tubing and transferred to a $50-\mathrm{mL} \mathrm{Corex}^{\circledR}$ tube. TBE $(0.5 \mathrm{X})$ 
was added to the tubing to collect most of the DNA. Rinsing was repeated until a volume of $12.5 \mathrm{~mL}$ had been collected.

The DNA was precipitated by adding 1/10th volume $(1.25 \mathrm{~mL}) 3 \mathrm{M}$ sodium acetate and 3 volumes absolute ethanol. It was mixed well, incubated at $-20^{\circ} \mathrm{C}$ for $2 \mathrm{~h}$, and centrifuged at $12,000 \mathrm{~g}$ for $40 \mathrm{~min}$, at $4^{\circ} \mathrm{C}$.

The supernatant was carefully discarded and $12.5 \mathrm{~mL} \mathrm{70 \%} \mathrm{ethanol} \mathrm{was} \mathrm{added.} \mathrm{The}$ Corex ${ }^{\circledR}$ tube was centrifuged again at $12,000 \mathrm{~g}$ for $40 \mathrm{~min}$, at $4^{\circ} \mathrm{C}$, with the pellet in the same position as in the first centrifugation.

The supernatant was again carefully discarded. The pellet was dried at room temperature and resuspended in $100 \mu \mathrm{L}$ TE, $\mathrm{pH} 8.0$ (10 mM Tris-HCl, $\mathrm{pH}$ 8.0, and 1 mM EDTA, $\mathrm{pH} 8.0$ ).

DNA concentration was measured in a spectrophotometer and adjusted to $1 \mu \mathrm{g} / \mu \mathrm{L}$ with distilled water for the bombardment experiments. The ahas fragment was utilized in transformation experiments as a selective marker gene.

\section{Microparticle bombardment and soybean transformation}

For particle bombardment experiments, $3 \mu \mathrm{g}$ DNA fragment was used for precipitation onto M10 tungsten microparticles. DNA precipitation and soybean transformation were carried out as previously described (Rech et al., 2008), and the plants were grown in a culture room. As soon as the shoots reached $2-4 \mathrm{~cm}$ in length and had rooted, they were transferred to a plastic pot containing autoclaved soil:vermiculite $(1: 1)$ and covered with a plastic bag for a week to acclimatize. In order to select putative transgenic lines, plantlets were sprayed with an aqueous solution containing imazapyr, at a rate of $50 \mathrm{~g} / \mathrm{ha}$. The surviving plants were further analyzed by PCR and Southern blot analysis.

\section{PCR analysis}

For PCR analysis, DNA was isolated from leaf disks of transformed plants according to Edwards et al. (1991). PCR was carried out according to Aragão et al. (2000). The primers 5'-ACTAGAGATTCCAGCGTCAC-3' (within the ahas promoter) and 5'-GTGGCTATACAGATACCTGG-3' (within the ahas coding sequence) were used to amplify a 685-bp sequence (Aragão et al., 2005).

\section{Southern blot analysis}

For Southern blot analysis, genomic DNA was isolated according to Dellaporta et al. (1983), and blotting and hybridization were carried out as previously described (Sambrook et al., 1989). Genomic DNA (15 $\mu \mathrm{g})$ was digested with SpeI or HindIII, separated on a 1\% agarose gel and transferred to a nylon Hybond membrane.

Hybridization was carried out using $60 \mathrm{ng}$ of the probe. For detection of the ahas gene, the 664-bp PCR product generated by the use of primers $5^{\prime}$ - TCC ATT GCT TCT GCT ATC GAC ACG - 3' and 5' - CCT CGG GAT TTG ATT TTT GGT CCT - 3' (probe $a$ - covering the ahas promoter) was used. For detection of the backbone of the pAC321 vector, a mix of probes $b, c$ and $d$ (20 ng each) was used. Probes $b, c$ and $d$ were obtained using the respective primers: 5' - GAG TAT TCA ACA TTT CCG TGT C - 3' and 5' - TAC CAA TGC TTA ATC 
AGT GAG GC - 3' (probe $b$, a fragment of 835 bp covering the amp region); 5' - TGT GAG CAA AAG GCC AGC AAA AG - 3' and 5' - TGA GCG TCA GAC CCC GTA GAA A - 3' (probe $c$, a fragment of $685 \mathrm{bp}$ covering the $E$. coli origin of replication); $5^{\prime}$ - CCG CTC CTT TCG CTT TCT TCC CTT - 3' and 5' - GGA CTC CAA CGT CAA AGG GCG A - 3' (probe $d$, a fragment of $200 \mathrm{bp}$ covering the phage $\mathrm{fl}$ origin of replication). The probes were labeled with $\alpha^{32} \mathrm{P}$ dCTP $(3000 \mathrm{Ci} / \mathrm{mol})$ using a random primer DNA labeling kit (Pharmacia Biotech) according to manufacturer instructions (Figure 1).

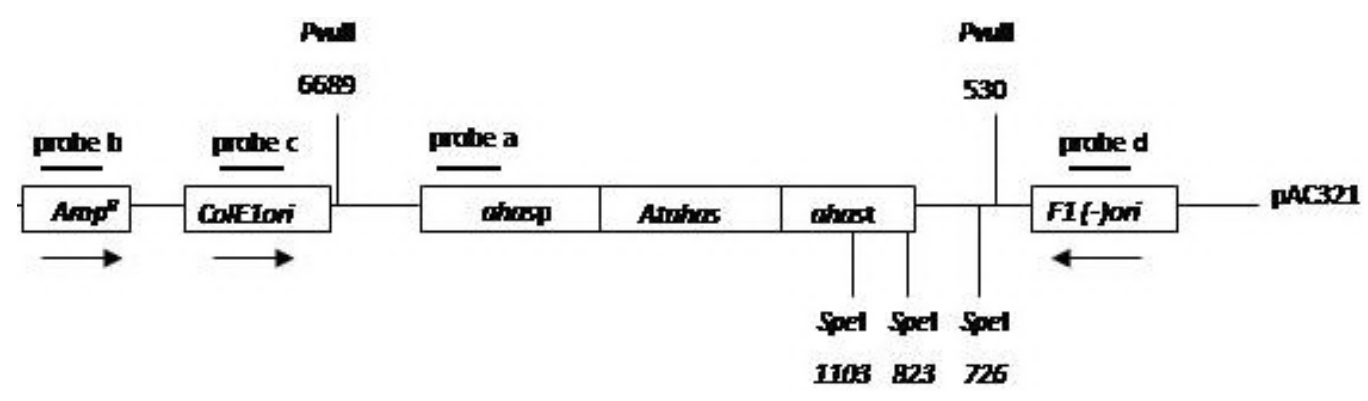

Figure 1. Schematic representation of the plasmid vector pAC321, showing the restriction sites (PvuII) used to obtain the 6159-bp ahas fragment from Arabidopsis thaliana (At), utilized for particle bombardment transformation of soybean embryos. The ahas gene is controlled both by the ahas promoter and terminator. The $A m p^{R}$ gene confers resistance to the antibiotic ampicillin.

\section{Plant cultivation}

The transgenic plants were cultivated, and the seeds collected $\left(\mathrm{R}_{1}\right.$ generation) were sown in 5- $\mathrm{dm}^{3}$ plastic pots containing autoclaved fertilized soil. Once the plants produced the first trifoliate leaves, they were sprayed with imazapyr at a commercial concentration of 100 $\mathrm{g} / \mathrm{ha}$. The surviving plants were analyzed by PCR for the presence of the ahas gene.

\section{RESULTS}

Seven transformation experiments using soybean cv. Conquista were performed, 1260 apical meristems of mature embryos were bombarded, and 1006 plantlets were obtained, having been grown in selective $500 \mathrm{nM}$ imazapyr medium. These acclimatized plantlets were sprayed with half the recommended rate of the herbicide Arsenal ${ }^{\mathbb{B}}(50 \mathrm{~g} / \mathrm{ha}$ imazapyr). About 15 days after spraying, the tolerant plants could be visually identified. Plants that were not tolerant to the herbicide had severe signs of toxicity. Red vein symptoms typically seen in imidazolinone-treated plants were observed in almost all tolerant plants, as described by Aragão et al., 2000. Ten plants survived the herbicide treatment and showed few signs of toxicity. All non-transgenic plants died after 15 days. All plants severely affected were discarded. The $\mathrm{R}_{0}$ transgenic plants were named E01, E02, E03, E04, E05, E06, E07, E08, E09, and E10. The transformation frequency was $0.8 \%$.

PCR analyses confirmed the presence of the ahas gene in all 10 tolerant plants, which were transferred to a plastic pot containing $5 \mathrm{dm}^{3}$ autoclaved fertilized soil and allowed to set seeds. 
The E09 line showed the best results and no symptoms of toxicity when $100 \mathrm{~g} / \mathrm{ha}$ imazapyr was applied on self-pollinated $\mathrm{R}_{1}$ seeds. Consequently, this line was chosen for further analyses up to the $\mathrm{R}_{4}$ generation. Southern blot analysis revealed that this line was homozygous and also showed the same hybridization pattern for all plants analyzed. It allowed us to confirm integration of the fragment as well as to estimate that this line contained one copy of the ahas gene integrated into the genome. It is a desirable property for transgenic plants in a breeding program aimed at product development. Genomic DNA isolated from non-transgenic plants did not hybridize with the ahas probe (Figure 2). Southern blot analysis of line E09 $\mathrm{R}_{4}$ plants, utilizing probes $b, c$ and $d$ concomitantly, did not render any hybridization signal, demonstrating the absence of other foreign genes and sequences (Figure 3).

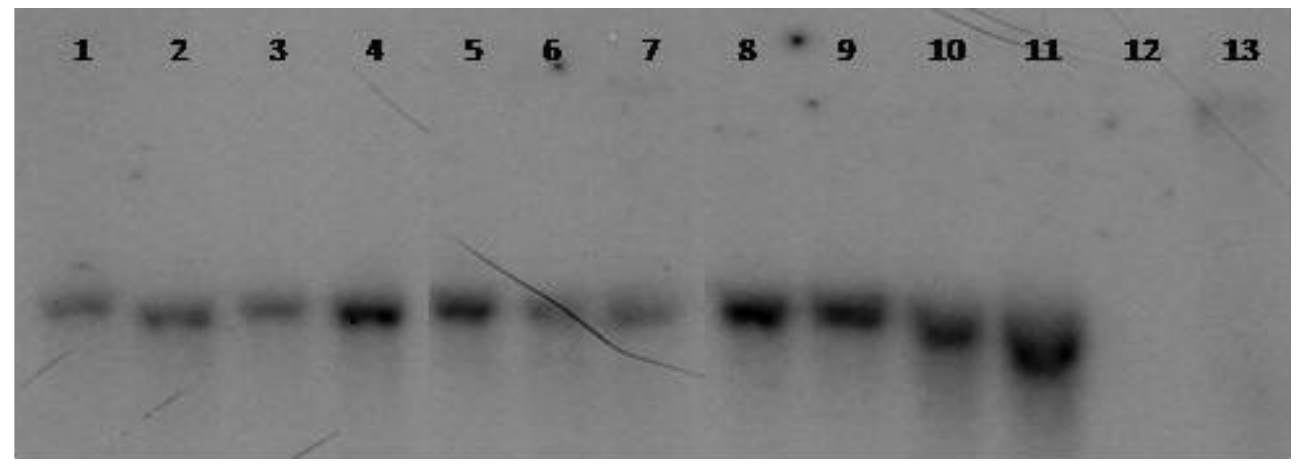

Figure 2. Southern blot of genomic DNA digested with SpeI, utilizing probe $a$ (Figure 1), from soybean plants in $\mathrm{R}_{3}$. Lanes 1 to $11=$ Progeny of transgenic line E09. Lane $12=$ Negative control. Lane $13=200 \mathrm{pg}$ entire pAC321 digested with SpeI.

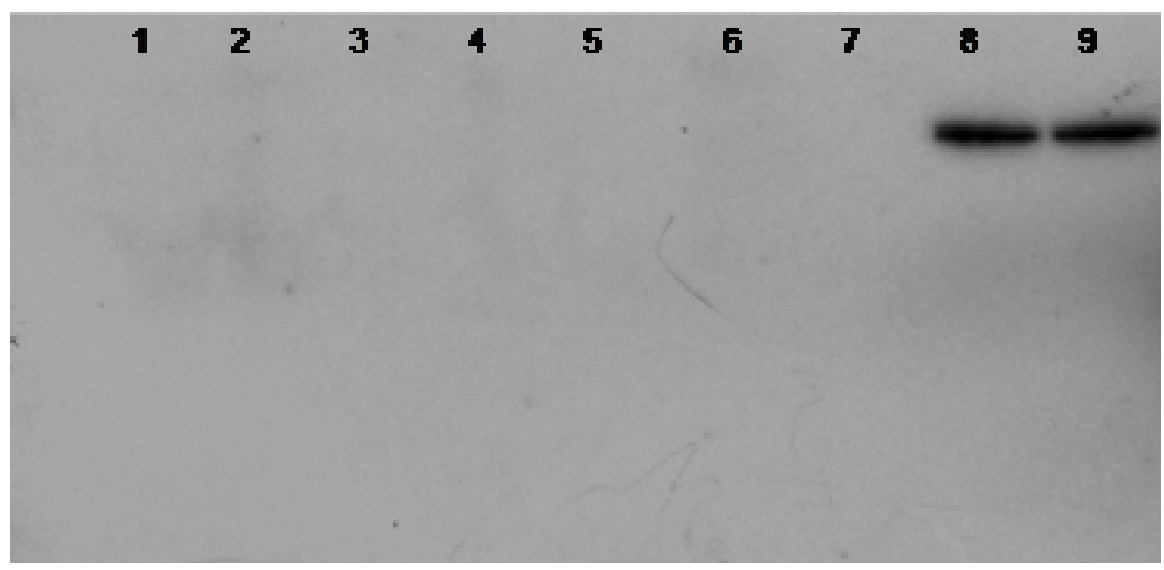

Figure 3. Southern blot of genomic DNA digested with HindIII, from progeny of transgenic E09 line $\mathrm{R}_{3}$, utilizing mixed probes $(b, c$ and $d$ ) (Figure 1) to detect the backbone vector. Lanes 1-6 = Progeny of transgenic line E09. Lane $7=$ Non-transgenic plant. Lanes 8 and $9=200$ pg of entire pAC321 digested with HindIII. 


\section{DISCUSSION}

We developed a methodology to obtain transgenic soybean plants containing only the gene(s) responsible for a desirable trait, avoiding the presence of antibiotic resistance genes commonly present in circular vectors. As a selective gene for this study, we used the mutated A. thaliana ahas gene under control of the ahas promoter and terminator. Although the purpose of this study was not to compare the efficiency of different systems using circular vectors, linear DNA fragments, or minimal cassettes to obtain transgenic soybeans, we observed a $0.8 \%$ frequency of plant transformation using fragments, showing that this method is useful in generating transgenic lines that could be introduced into a breeding program.

Since the plants were selected using $50 \mathrm{~g} / \mathrm{ha}$ imazapyr, it is expected that many transgenic events with a low level of transgene expression were unable to further develop, because all plants were grown in vitro, in a medium containing $500 \mathrm{nM}$ imazapyr. Therefore, considering the effect of transgene position, and other factors that prevent high-level expression of the transgene, the percentage of transformation may be far greater than the $0.8 \%$ observed. Aragão et al. (2000) obtained a 3.9 to $20.1 \%$ transformation frequency with a system based on the use of imazapyr; however, only $9 \%$ of the transgenic plants obtained in their study ( 3 in 35 plants), showed no symptoms after herbicide application of $100 \mathrm{~g} / \mathrm{ha}$, which is directly related to the level of transgene expression. If we consider this percentage in our study, we can estimate a transformation frequency of about $11 \%$.

$\mathrm{Fu}$ et al. (2000) observed a higher transformation frequency for rice, using DNA fragments in substituting circular vectors. For bean transformation, Vianna et al. (2004) observed that the frequency was similar whether they used a fragment or an entire vector. Here, we did not generate enough data to reach a clear conclusion, but the transformation frequencies in both cases are apparently very similar.

During the transgene integration process of the foreign sequence into the plant genome, it is possible to undergo losses in DNA sequences at $5^{\prime}$ and $3^{\prime}$ ends of the cassette, with the subsequent loss of diagnostic fragments and eventually loss of transgene expression (Vidal et al., 2006). Therefore, when choosing the restriction enzyme, it is important to consider leaving at least $100 \mathrm{bp}$ at the ends of the expression cassette. This was considered in our case, and the ends were 247 and $201 \mathrm{bp}$ on the $5^{\prime}$ and $3^{\prime}$ sides, respectively. We can infer that the ahas cassette was complete in the plant genome, since the plants from event E09 tolerated applications of up to $140 \mathrm{~g} / \mathrm{ha}$ imazapyr, without damage to the plants, indicating a high level of expression of the ahas gene, at a dose $40 \%$ higher than commercially recommended.

Questions regarding biosafety issues have been raised because of the presence of genes for antibiotic resistance in transgenic plants (Dale, 1999), and sequences coding for antibiotic resistance are consequently being avoided for the development of new marketable varieties. In addition, the vectors serve no purpose in direct DNA transfer procedures, especially particle bombardment (Fu et al., 2000). The results obtained demonstrated the feasibility of the introduction of a DNA fragment containing only the desirable expression cassette to obtain new soybean varieties by microparticle bombardment.

The study presented shows a reproducible methodology for the introduction of DNA fragment into the genome of soybean plants, containing only the promoter, the coding sequence and terminator of interest, while avoiding the use of genes for antibiotic resistance and other undesirable sequences. The technology described has been used in our laboratory 
to obtain transgenic soybean containing other genes (Cunha et al., 2010) and has created the foundation for obtaining herbicide-resistant soybean elite events, jointly developed by Embrapa and BASF, which should be available commercially in 2011.

\section{ACKNOWLEDGMENTS}

Research supported in part by BASF, Empresa Brasileira de Pesquisa Agropecuária (EMBRAPA) and Conselho Nacional de Desenvolvimento Científico (CNPq). The authors are grateful to Warley Almeira and Luís Carlos Lemos for technical assistance.

\section{REFERENCES}

Aragão FJL, Sarokin L, Vianna GR and Rech EL (2000). Selection of transgenic meristematic cells utilizing a herbicidal molecule results in the recovery of fertile transgenic soybean [Glycine $\max (\mathrm{L}$.) Merril] plants at a high frequency. Theor. Appl. Genet. 101: 1-6.

Aragão FJL, Vianna GR, Albino MMC and Rech EL (2002). Transgenic dry bean tolerant to the herbicide glufosinate ammonium. Crop Sci. 42: 1298-1302.

Aragão FJL, Vianna GR, Carvalheira SBRC and Rech EL (2005). Germ line genetic transformation in cotton (Gossypium hirsutum L.) by selection of transgenic meristematic cells with a herbicide molecule. Plant Sci. 168: 1227-1233.

Artelt P, Grannemann R, Stocking C, Friel J, et al. (1991). The prokaryotic neomycin-resistance-encoding gene acts as a transcriptional silencer in eukaryotic cells. Gene 99: 249-254.

Cheng YQ, Yang J, Xu FP, An LJ, et al. (2009). Transient expression of minimum linear gene cassettes in onion epidermal cells via direct transformation. Appl. Biochem. Biotechnol. 159: 739-749.

Cunha NB, Araujo AC, Leite A, Murad AM, et al. (2010). Correct targeting of proinsulin in protein storage vacuoles of transgenic soybean seeds. Genet. Mol. Res. 9: 1163-1170.

Dale PJ (1999). Public concerns over transgenic crops. Genome Res. 9: 1159-1162.

Dellaporta SL, Wood J and Hicks JB (1983). A plant DNA minipreparation: Version II. Plant Mol. Biol. Rep. 1: 19-21.

Edwards K, Johnstone C and Thompson C (1991). A simple and rapid method for the preparation of plant genomic DNA for PCR analysis. Nucleic Acids Res. 19: 1349.

Fu X, Duc LT, Fontana S, Bong BB, et al. (2000). Linear transgene constructs lacking vector backbone sequences generate low-copy-number transgenic plants with simple integration patterns. Transgenic Res. 9: 11-19.

Gao XR, Wang GK, Su Q, Wang Y, et al. (2007). Phytase expression in transgenic soybeans: stable transformation with a vector-less construct. Biotechnol. Lett. 29: 1781-1787.

Jakowitsch J, Papp I, Moscone EA, van der Winden J, et al. (1999). Molecular and cytogenetic characterization of a transgene locus that induces silencing and methylation of homologous promoters in trans. Plant J. 17: 131-140.

Liu M, Yang J, Cheng YQ and An LJ (2009). Optimization of soybean (Glycine max (L.) Merrill) in planta ovary transformation using a linear minimal gus gene cassette. J. Zhejiang Univ. Sci. B 10: 870-876.

Miki B and McHugh S (2004). Selectable marker genes in transgenic plants: applications, alternatives and biosafety. $J$. Biotechnol. 107: 193-232.

Muller AE, Kamisugi Y, Gruneberg R, Niedenhof I, et al. (1999). Palindromic sequences and A+T-rich DNA elements promote illegitimate recombination in Nicotiana tabacum. J. Mol. Biol. 291: 29-46.

Nunes AC, Vianna GR, Cuneo F, Amaya-Farfan J, et al. (2006). RNAi-mediated silencing of the myo-inositol-1-phosphate synthase gene (GmMIPS1) in transgenic soybean inhibited seed development and reduced phytate content. Planta 224: $125-132$.

Rech EL, Vianna GR and Aragao FJ (2008). High-efficiency transformation by biolistics of soybean, common bean and cotton transgenic plants. Nat. Protoc. 3: 410-418.

Sambrook J and Russell DW (2001). Molecular Cloning: A Laboratory Manual. Cold Spring Harbor Laboratory Press, Cold Spring Harbor.

Sambrook J, Fritsch EF and Maniats T (1989). Molecular Cloning: A Laboratory Manual. Cold Spring Harbor Laboratory Press, New York.

Sathasivan K, Haughn GW and Murai N (1990). Nucleotide sequence of a mutant acetolactate synthase gene from an imidazolinone-resistant Arabidopsis thaliana var. Columbia. Nucleic Acids Res. 18: 2188.

Tinoco ML, Vianna GR, Abud S, Souza PIM, et al. (2006). Radiation as a tool to remove selective marker genes from 
transgenic soybean plants. Biol. Plantarum 50: 146-148.

US Food and Drug Administration (US FDA) (1998). Guidance for Industry: Use of Antibiotic Resistance Marker Genes in Transgenic Plants. Draft Guidance, September 4, Rockville.

Vianna GR, Albino MMC, Dias BBA, Silva LM, et al. (2004). Fragment DNA as vector for genetic transformation of bean (Phaseolus vulgaris L.). Sci. Hortic. 99: 371-378.

Vidal JR, Kikkert JR, Donzelli BD, Wallace PG, et al. (2006). Biolistic transformation of grapevine using minimal gene cassette technology. Plant Cell Rep. 25: 807-814.

Zhao Y, Qian Q, Wang H and Huang D (2007). Hereditary behavior of bar gene cassette is complex in rice mediated by particle bombardment. J. Genet. Genomics 34: 824-835. 